\title{
Quantificação de tecido conjuntivo do músculo cardíaco em equinos de tração através de técnicas histoquímicas e morfométricas
}

\author{
Quantification of connective tissue in cardiac muscle from horses used for traction using \\ histochemical and morphometric techniques \\ Eduardo Maurício Mendes de Lima ${ }^{I^{*}}$ Marcelo Ismar Silva Santana ${ }^{\mathrm{I}}$ \\ Márcio Botelho de Castro ${ }^{\mathrm{I}}$ Pedro Primo Bombonato ${ }^{\mathrm{II}}$ Hildebrando Gomes Benedicto ${ }^{\mathrm{III}}$ \\ André Rodrigues da Cunha Barreto Vianna
}

\section{RESUMO}

Os cardiomiócitos são sustentados e inseridos em um esqueleto de tecido conjuntivo, este possui distribuição desigual de acordo com as propriedades das distintas regiões em que se encontra. O propósito deste estudo foi quantificar a proporção de tecido conjuntivo em relação à disposição de cardiomiócitos dos ventrículos direito e esquerdo e no septo interventricular do miocárdio de seis equinos subnutridos adultos, sendo quatro machos e duas fêmeas, sem raça definida e utilizados para tração. Com auxílio de paquímetro eletrônico digital, avaliou-se a altura do ventrículo esquerdo, a largura do coração, assim como sua circunferência, as espessuras das paredes livres dos ventrículos e do septo interventricular. Os fragmentos relativos ao terço médio do septo interventricular e das paredes livres dos ventrículos foram submetidos à técnica histológica convencional. Os blocos foram cortados com espessura de $5 \mu \mathrm{m}$ e corados com Picrosirius Red, Tricromo de Gomori e Tricromo de Azan para evidenciação do tecido conjuntivo. As lâminas foram analisadas com uso do microscópio óptico digital acoplado ao programa de análise de imagens Image-Pro Plus ${ }^{\circledR}$. A proporção média de tecido conjuntivo no ventrículo esquerdo foi de $6,1 \pm 3,7 \%$, no septo interventricular foi obtida a média de $6,8+3,6 \%$ e no ventrículo direito a média foi de $6,1+3,1 \%$. Ao aplicarmos teste $H$ de Kruskal-Wallis, verificamos que ocorreu diferença estatística entre os diferentes corantes utilizados em relação às regiões avaliadas. No teste de correlação de Pearson, não foi encontrado padrão de correlação entre a espessura das regiões analisadas e a proporção de tecido conjuntivo.

Palavras-chave: coração, morfometria, miocárdio, cardiomiócitos.

\section{ABSTRACT}

Cardiomyocytes are sustained and inserted into a connective tissue skeleton that has different distribution depending up on the properties of the region in which it stands.
The purpose of this study was to quantify the proportion of connective tissue in relation to the arrangement of cardiomyocytes of left and right ventricles and interventricular septum in myocardium of six mixed breed, ill trifted adult horses, of both sexes, used for traction. With hearts still fresh and with the aid of a digital caliper, it was estimated the height of left ventricle, the heart's width, the heart's circumference and the thickness of the ventricular free walls and interventricular septum. The fragments on the middle third of the interventricular septum and free walls of the ventricles were subjected to conventional histological technique. The blocks were cut with thickness of $5 \mu \mathrm{m}$ and stained with Picrosirius Red, Gomori Trichrome and Azan Trichrome to show the connective tissue. The slides were analyzed using optical microscope coupled to a digital analysis program Image-Pro Plus ${ }^{\circledR}$. The average proportion of connective tissue in the left ventricle was $6.1 \pm 3.7 \%$, in the interventricular septum and it was observed a mean of $6.8 \pm 3.6 \%$. In the right ventricle the average was $6.0+3.0 \%$. Applying the H test of Kruskal-Wallis, it was found that there was statistical difference between the different dyes used for each region. In the Pearson correlation test it was not found pattern correlation between the thickness of the regions analyzed and the proportion of connective tissue

Key words: heart, morfometry, myocardium, cardiomyocytes.

\section{INTRODUÇÃO}

Os equinos usados para tração de veículos, principalmente na área urbana, são submetidos a uma forma de vida totalmente diferente. Eles não dispõem de alimentação e repouso compatíveis com a atividade

Instituto Central de Ciência, Universidade de Brasília (UnB), Campus Universitário Darcy Ribeiro, Ala Sul, CP 4508, 70910-970, Brasília, DF, Brasil. E-mail: limaemm@unb.br. *Autor para correspondência.

IFaculdade de Medicina Veterinária e Zootecnia, Universidade de São Paulo (USP), São Paulo, SP, Brasil.

IIIDepartamento de Morfologia, Universidade Federal Fluminense (UFF), Niterói, RJ, Brasil. 
física desenvolvida diariamente e têm de se adaptar a ambientes e alimentações bem diversas daquelas naturais, frequentemente inadequados à sua anatomia e fisiologia (SMYTHE, 1990; MACIEL et al., 2008).

Esses animais necessitam de um sistema circulatório bastante eficiente, principalmente em relação ao coração, que deve desempenhar ativamente sua função de garantir o aporte sanguíneo para todo o organismo. Devido à estreita relação existente entre o coração e o exercício físico, torna-se interessante o conhecimento das adaptações realizadas por esse órgão em situações de debilitação nutricional. Essas debilitações promovem alterações de âmbito bioquímico que influenciam diretamente no desempenho de diversos sistemas, agindo de maneira diferente nos diversos órgãos e tecidos do organismo (FREITAS et al., 1994; CURY, 2006).

Diante desse contexto, pode-se ver que a musculatura cardíaca é sustentada e inserida em um esqueleto de tecido conjuntivo, que tem como principais componentes as fibras colágenas, reticulares e elásticas. Suas distribuições são desiguais entre as diferentes variedades de tecidos e responsáveis por certas propriedades destes (JUNQUEIRA \& CARNEIRO, 1995). A principal função do tecido conjuntivo é a de suporte e auxílio na manutenção do alinhamento dos cardiomiócitos. Devido a sua tensão a distensão e elasticidade, ele resiste à deformação, preservando a forma e espessura, prevenindo rupturas e contribuindo para o enrijecimento passivo e ativo do miocárdio. Já o colágeno possui uma relação direta com o processo de envelhecimento, apresentando mudanças definidas conforme a idade (DEBESSA et al., 2001; MARTOS et al., 2007).

O esforço físico aumentado gera respostas compensatórias do miocárdio, como, por exemplo, alteração na deposição de tecido conjuntivo, hipertrofia e remodelamento cardíaco, pois a hiperfunção miocárdica induz à injúria miocárdica e ao aumento de tamanho dos cardiomiócitos, provocando um aumento de massa e tamanho generalizado do coração (ROSSI, 1998).

Portanto, o objetivo deste trabalho foi quantificar a proporção de tecido conjuntivo em relação aos cardiomiócitos no coração de equinos de tração. Observando ainda a forma e o tamanho das fibras colágenas em relação às diferenças existentes na morfologia cardíaca, relativas às adaptações do músculo cardíaco adquiridas nesses animais.

\section{MATERIAL E MÉTODOS}

Foram empregados neste estudo seis corações de equinos adultos, sendo quatro machos e duas fêmeas, utilizados para tração de carroças, com escore corporal compatível com o estado de subnutrição e desprovidos de patologias cardíacas. A coleta desses órgãos foi realizada de animais que morreram no Hospital Veterinário de Grandes Animais da Faculdade de Agronomia e Medicina Veterinária da Universidade de Brasília.

Com os corações ainda a fresco, foram tomadas, com auxílio de um paquímetro eletrônico digital 727-6/150 $\left(\right.$ Starrett $\left.^{\circledR}\right)$ e fita métrica, medidas relativas da altura ventricular esquerda, compreendida entre o sulco coronário, na margem ventral do coração, e seu ápice; largura do coração, tomada da face cranial até a caudal na altura do sulco coronário e circunferência do coração, obtida na altura do sulco coronário. Em seguida, os corações foram seccionados, sendo retirado fragmento do terço médio da parede livre dos ventrículos direito e esquerdo, entre as faces esquerda e direita, e do terço médio do septo interventricular. Desses fragmentos, foram feitas mensurações referentes à sua espessura.

Os fragmentos coletados foram fixados por cerca de 48 horas em solução aquosa de formaldeído a $10 \%$ e posteriormente em álcool hidratado $70 \%$, clivados em direção perpendicular às fibras musculares e tratados segundo a técnica histológica convencional. Com auxílio de micrótomo manual (Spencer-Lens Co.), foram produzidas lâminas com espessura de $5 \mu \mathrm{m}$.

Para evidenciação e diferenciação do tecido conjuntivo, as lâminas foram coradas com três métodos de coloração distintos: Tricromo de Gomori, Tricromo de Azan e Picrosirius Red. As imagens foram captadas com microscópio óptico BX51 Olympus ${ }^{\circledR}$, utilizando aumento de 10x e analisadas com o software Image-Pro Plus $^{\circledR}$, mensurando o tecido conjuntivo em dez campos distintos.

Estatisticamente, os dados coletados foram analisados diante dos diferentes corantes, foram avaliados utilizando-se estatística descritiva e relacionados com os valores macroscópicos do coração, empregando o teste de correlação de Pearson. Os diferentes corantes foram avaliados ainda empregando-se o teste $\mathrm{H}$ de Kruskal-Wallis, verificando se houve diferença estatística entre a proporção do tecido conjuntivo e cardiomiócitos, com nível de significância de $5 \%$.

\section{RESULTADOS E DISCUSSÃO}

As fibras de colágeno possuem a importante função de manter o tamanho e formato do coração (LEGRICE etal., 1995; CAULFIELD \& JANICKI, 1997), sendo estas o componente principal do tecido 
conjuntivo (BLUMENFELD \& SEIFTER, 1990; LEITE et al., 2004) e parte fundamental na estrutura do coração. Os autores JALIL et al. (1989) e WEBER et al. (1994) citaram que modificações nessa malha de tecido conjuntivo podem levar a disfunções elétricas e mecânicas relacionadas a alterações no desempenho deste órgão. Desse modo, o conhecimento desse tecido mostrou-se imprescindível para o melhor conhecimento dos mecanismos envolvidos nestas alterações e, portanto, da morfofisiologia do coração.

As medidas macroscópicas do coração dos equinos deste estudo revelaram: altura do ventrículo esquerdo $21,00 \pm 2,43 \mathrm{~cm}$, largura do coração $18,08 \pm 1,96 \mathrm{~cm}$, circunferência do coração $47,08 \pm 3,47 \mathrm{~cm}$, espessura do terço médio da parede livre do ventrículo esquerdo $4,31 \pm 0,72 \mathrm{~cm}$, espessura do terço médio do septo interventricular $4,31 \pm 1,38 \mathrm{~cm}$ e espessura do terço médio da parede livre do ventrículo direito $2,15 \pm 0,59 \mathrm{~cm}$.

Em equinos da raça PSI (LEITE et al., 2004), as espessuras dos ventrículos direito e esquerdo apresentaram-se muito superiores às encontradas no presente estudo, sugerindo que essa variação seja devida tanto a características da raça, como também relativas à hipertrofia, decorrente da atividade física que os animais exerceram durante a vida, já que a espessura da camada miocárdica é proporcional ao volume de trabalho executado (PELLICCIA \& MARON, 2001).

$\mathrm{Na}$ análise microscópica, observou-se, ao corte transversal do miocárdio, a disposição das fibras de tecido conjuntivo circundando os cardiomiócitos em uma complexa hierarquia de organização, possuindo direção paralela a elas mesmas e com aspecto de favo de mel (Figura 1). Esse arranjo estrutural da relação entre os cardiomiócitos e o tecido conjuntivo foi caracterizado nos trabalhos de FRANK \& LANGER (1974) em coelhos, ROBINSON et al. (1983), VRACKO et al. (1989), BASHEY et al. (1992) e ADÈLE et al. (2008) em ratos, ICARDO \& COLVEE (1998) e SÁNCHEZQUINTANA et al. (1999) em humanos, BASHEY et al. (1992) em macacos, BASHEY et al. (1992), LEGRICE et al. (1995) e BENEDICTO \& BOMBONATO (2003) em cães e LEITE et al. (2004) em equinos da raça PSI. Dessa forma, mostrou-se similar nas diferentes espécies de mamíferos. Porém, poucos estudos (FRANK \& LANGER, 1974; MEDUGORAC, 1982; BENEDICTO \& BOMBONATO, 2003; LEITE et al., 2004) tiveram o propósito de quantificar esse tecido nas diferentes porções do coração, como foi objetivado nesta pesquisa.

$\mathrm{Na}$ avaliação da proporção de tecido conjuntivo em equinos de tração, verificou-se que a distribuição dele variou ao longo das regiões do coração. Essa variação também foi observada em ratos

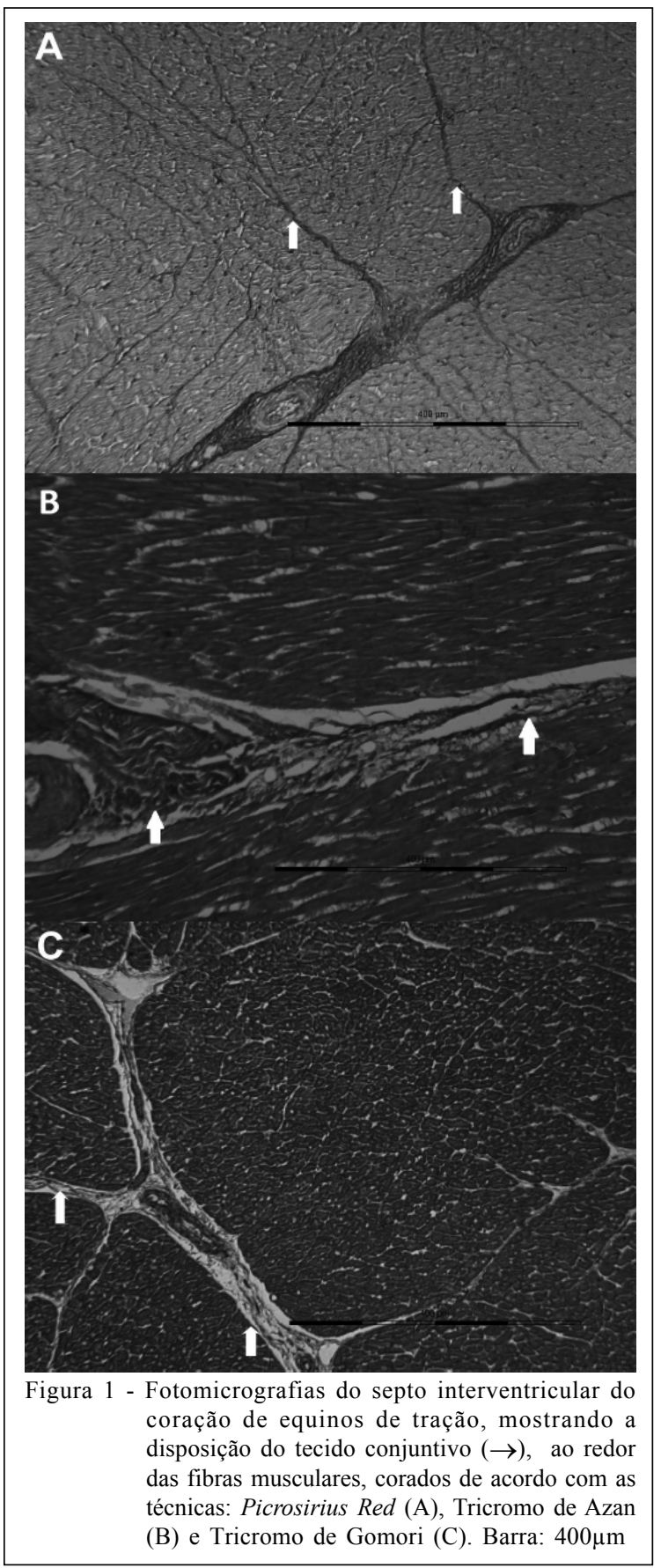

(ROBINSON et al., 1983), cães (LEGRICE et al., 1995; BENEDICTO \& BOMBONATO, 2003), humanos (ICARDO \& COLVEE, 1998) e equinos PSI (LEITE et al., 2004). Esses achados coincidiram com os informes de LEITE et al. (2004), quando mencionaram que este arranjo relacionou-se com os diferentes requerimentos dinâmicos do coração, como, por exemplo, a resistência às dramáticas mudanças de sua forma durante seu ciclo. Conforme FRANK \& LANGER (1974), MEDUGORAC (1982), BENEDICTO \& BOMBONATO

Ciência Rural, v.41, n.6, jun, 2011. 
(2003) e LEITE et al. (2004), foi possível notar a falta de relação de igualdade na proporção de tecido conjuntivo entre as mesmas regiões do coração em diferentes espécies. Já MEDUGORAC (1982), ao estudar a proporção de tecido conjuntivo no ventrículo esquerdo de diversos mamíferos, concluiu que, em ratos, existem em média $2,2 \%$ de tecido conjuntivo nesta porção, já, em porcos e coelhos, encontrou 3,2\% e, em gatos, vacas e cães, 3,8\%. Esse valor mostrou-se abaixo do encontrado por BENEDICTO \& BOMBONATO (2003) de 9,51\% com Picrosirius Red e 6,38\% com Tricromo de Gomori no mesmo ventrículo em cães, sobretudo no ventrículo direito foi encontrado $9,03 \%$ com Picrosirius Red e 7,58\% com Tricromo de Gomori, revelando, com isso, dados distintos para a mesma espécie. FRANK \& LANGER (1974) estudaram o espaço extracelular do miocárdio do septo em coelhos, no entanto, não descreveram se foi usada a porção do septo interventricular ou do septo interatrial e concluíram que este possuiu em média 3,9\% de fibras colágenas, ou seja, média de $0,88 \%$ do total de tecido. Em equinos da raça PSI (LEITE et al., 2004), foi observado em média $3,31 \%$ de tecido conjuntivo no ventrículo esquerdo e $3,45 \%$ no ventrículo direito. De outra forma, em equinos de tração, a proporção média desse tecido foi de $6,1 \pm 3,7 \%$ para o ventrículo esquerdo, $6,8 \pm 3,6 \%$ para o septo interventricular e $6,1 \pm 3,1 \%$ para o ventrículo direito, sugerindo particularidades próprias para esses animais, caracterizando a possibilidade da influência de fatores extrínsecos, tais como, condição nutricional, idade e tipo de exercício a que os animais foram submetidos durante a vida, em relação à proporção destes tecidos nas diferentes regiões do coração.

Foi possível entender que a proporção de tecido conjuntivo do miocárdio mostrou-se como uma característica particular de cada espécie, podendo ser diferente entre as diversas raças e ainda sofrendo influência do requerimento cardíaco da atividade física que o animal exerceu, acrescidos da nutrição destes animais. Estudos com cães (ABEL et al., 1979; ALDEN et al. 1987) e ratos (FIORETTO et al., 2001) demonstraram que, em animais que receberam dieta pobre em proteínas e calorias, houve uma diminuição do diâmetro e do volume dos cardiomiócitos, sobretudo com o aumento da quantidade de colágeno e, consequentemente, diminuição da relação de volume entre cardiomiócitos e interstício. Dessa forma, quando comparamos animais de mesma espécie, porém com estilo de vida diferenciado, como foi o caso dos equinos da raça PSI (LEITE et al., 2004) e os equinos deste trabalho, que apresentavam escore corporal compatível com animais subnutridos, sugere-se então que o resultado seja uma justificativa para as maiores proporções de tecido conjuntivo neste órgão, podendo até mesmo sobrepor o aumento da quantidade de tecido conjuntivo que foi observado no coração hipertrofiado de animais atletas, como foi o caso dos equinos PSI.

Assim como MAYS et al. (1991), DEBESSA et al. (2001), BENEDICTO \& BOMBONATO (2003), LEITE et al. (2004) e MARTOS et al. (2007), foi observado neste estudo a existência de correlação positiva entre a idade dos animais, a quantidade de tecido conjuntivo e os cardiomiócitos. Isso levou a crer na existência de mecanismos que interferiram no aumento da proporção de tecido conjuntivo, tal como o avanço da idade. Sobretudo, esse fator ainda não foi muito bem esclarecido, mas evidências mostraram a possibilidade da existência de alterações na metabolização deste tecido em decorrência da idade (MARTOS et al., 2007).

$\mathrm{O}$ teste $\mathrm{H}$ de Kruskal-Wallis demonstrou que o método de quantificação do tecido conjuntivo utilizando a coloração Picrosirius Red apresentou diferença estatística na porção do ventrículo esquerdo e do septo interventricular, quando comparado com os corantes Tricromo de Gomori e Tricromo de Azan para os animais estudados. De outra forma, não houve diferença estatística no ventrículo direito entre os dois corantes tricrômicos. Em relação ao teste de correlação de Pearson, foi constatado que não houve um padrão de correlação entre a proporção de tecido conjuntivo existente nas regiões analisadas e os dados métricos avaliados para as diferentes regiões (Tabela 1).

\section{CONCLUSÃO}

O tecido conjuntivo participou ativamente da arquitetura do miocárdio, suas fibras englobaram os cardiomiócitos, apresentando a mesma direção e possuindo, ao corte transversal, aspecto visual de favo de mel. Os corantes Tricromo de Gomori, Tricromo de Azan e Picrosirius Red se revelaram eficientes na visualização deste tecido, sobretudo ao serem analisados empregando-se o teste $\mathrm{H}$ de Kruskal-Wallis, estes mostraram diferença estatística entre o corante Picrosirius Red e os Tricrômos de Gomori e Azan.

A proporção média de tecido conjuntivo no ventrículo esquerdo foi de $6,1 \pm 3,7 \%$, no septo interventricular foi obtida a média de $6,8 \pm 3,6 \%$ e no ventrículo direito a média foi de $6,1 \pm 3,1 \%$.

Diante da aplicação do teste de correlação de Pearson, os dados referentes à proporção de tecido conjuntivo no miocárdio não apresentaram um padrão de correlação em relação à análise macroscópica do coração dos animais deste estudo, sendo encontradas correlações tanto positivas como negativas, moderadas e fracas. 


\section{COMITÊ DE ÉTICA E BIOSEGURANÇA}

Esta pesquisa foi analisada e aprovada pelo Comitê de ética no uso animal da Universidade de Brasília, sob protocolo n.46489/2009.

\section{FONTE FINANCIADORA}

Este estudo foi financiado pela Fundação de Empreendimentos Científicos e Tecnológicos - FINATEC.

\section{REFERÊNCIAS}

ABEL, R.M. et al. Adverse hemodynamic and ultrastructural changes in dog hearts subjected to protein-calorie malnutrition. American Heart Journal, v.97, p.733-744, 1979.

ADÈLE J.P. et al. Three-dimensional transmural organization of perimysial collagen in the heart. American Journal of Physiology: Heart and Circulatory Physiology, v.295, p.H1243-H1252, 2008. Disponível em: <http://www.ncbi.nlm.nih.gov/pmc/articles/PMC2544485/ ?report=printable $>$. Acesso em: 24 abr. 2011. doi:10.1152/ ajpheart.00484.2008.

ALDEN P.B. et al. Left ventricular function in malnutrition. American Journal of Physiology: Heart and Circulatory Physiology, v.253, p.H380-H387, 1987.

BASHEY, R.I. et al. Isolation, characterization and localization of cardiac collagen Type VI: associations with other extracellular matrix components. Circulation Research, v.70, p.1006$1017,1992$.

BENEDICTO, H.G.; BOMBONATO, P.P. Quantificação de tecido conjuntivo do músculo cardíaco de cães. Brazilian Journal of Veterinary Research and Animal Science, v.40, n.2, p.108-116, 2003. Disponível em: <http:// www.scielo.br/scielo.php?script $=$ sci $\operatorname{arttext\& pid}=\mathrm{S} 1413$ $95962003000200004 \& \operatorname{lng}=\mathrm{en} \& \mathrm{nrm}=\mathrm{i}$ so \&t $\operatorname{lng}=\mathrm{pt}>$. Acesso em: 24 abr. 2011. doi: 10.1590/S1413-95962003000200004.

BLUMENFELD, O.O.; SEIFTER, S. Biochemistry of connective tissue with special emphasis on the heart. In: ROBINSON, T.F.; KINNE, R.K.H. Cardiac myocyteconnective tissue interactions in health and disease. Experimental Biology and Medicine, v.13. p.5-36, 1990.

CAULFIELD, J.B.; JANICKI, J.S. Structure and function of myocardial fibrillar collagen. Technology and Health Care, v.5, p95-113, 1997.

CURY, J.C.S. Estudo histomorfométrico pré e pós-natal dos cardiomiócitos ventriculares de ratos submetidos à desnutrição protéica. 2006. 42f. Dissertação (Mestrado em Educação Física) - Curso de Pós-graduação em Educação Física, Universidade São Judas Tadeu, São Paulo, SP.

DEBESSA, C.R.G. et al. Age related changes of the collagen network of the human heart. Mechanisms of Ageing and Development, v.122, n.13, p.1049-1058, 2001.

FIORETTO, J.R. et al. Ventricular remodeling and diastolic myocardial dysfunction in rats submitted to protein-calorie malnutrition. American Journal of Physiology, v.282, p.H1327H1333, 2001. Disponível em: <http://ajpheart.physiology.org/ content/282/4/H1327.full>. Acesso em: 24 abr. 2011. doi:10.1152/ ajpheart.00431.2001.

FRANK, J.S.; LANGER, G.A. The myocardial interstitium: its structure and its role in ionic exchange. Journal of Cell Biology, v.60, n.3, p.586-601, 1974

FREITAS, R.A. et al. Morphological and morphometric analysis of the parotid glands of rats submitted to different levels of protein deficiency. Revista de Odontologia da Universidade de São Paulo, v.8, n.1, p.43-49, 1994.

ICARDO, J.M.; COLVEE, E. Collagenous skeleton of the human mitral papillary muscle. Anatomical Record, v.252, n.4, p.509518, 1998. Disponível em: <http://onlinelibrary.wiley.com/doi/ 10.1002/(SICI) 1097-0185(199812)252:4\%3C509::AIDAR2\%3E3.0.CO;2-O/abstract>. Acesso em: 24 abr. 2011. doi: 10.1002/(SICI)1097-0185(199812)252.

JALIL, J.E. et al. Fibrillar collagen and myocardial stiffness in the intact hypertrophied rat left ventricle. Circulation Research, v.64, p.1041-1050, 1989.

JUNQUEIRA, L.C.; CARNEIRO, J. Histologia básica. 8.ed. Rio de janeiro: Guanabara Koogan, 1995. p.69-93, 170-173.

LEGRICE I.J. et al. Laminar structure of the heart: ventricular myocyte arrangement and connective tissue architecture in the dog. American Journal of Physiology: Heart and Circulatory Physiology, v.269, p.H571-H582, 1995.

LEITE, E.P. et al. Morfometria do tecido conjuntivo do coração de equinos PSI. Brazilian Journal of Veterinary Research and Animal Science, v.41, n.3, p.295-300, 2004. Disponível em: $<$ http://www.scielo.br/scielo.php?script=sci_arttext\&pid=S1413$95962004000300003 \& \operatorname{lng}=$ en\&nrm $=\mathrm{iso \& t} \ln \mathrm{g}=\mathrm{pt}>$. Acesso em: 24 abr. 2011. doi: 10.1590/S1413-95962004000300003.

MACIEL, R.M. et al. Perfil hematológico e parasitológico de equinos utilizados na tração de carroças no município de Santa 
Maria - RS. In: CONBRAVET, 2008, Gramado - RS. Anais... Gramado: SOVERGS, 2008. Disponível em: <http:// www.sovergs.com.br/conbravet2008/anais/cd/resumos/R10401.pdf>. Online. Acesso em: 25 abr. 2011.

MARTOS, R.J. et al. Diastolic heart failure: evidence of increased myocardial collagen turnover linked to diastolic dysfunction circulation. Circulation Research, v.115, n.7, p.888-895, 2007. Disponível em: <http://circ.ahajournals.org/cgi/content/ full/115/7/888>. Acesso em: 24 abr. 2011. doi: 10.1161/ CIRCULATIONAHA.106.638569.

MAYS, P.K. et al. Age-related changes in collagen synthesis and degradation in rat tissues. Biochemical Journal, v.276, p.307-313, 1991

MEDUGORAC, I. Caracterization of intramuscular collagen in the mammalian left ventricule. Basic Research in Cardiology, v.77, p.589-598, 1982.

PELLICCIA, A.; MARON, B.J. Athlete's heart electrocardiogram mimicking hypertrophic cardiomyopathy. Current Cardiology Reports, v.3, p.147-151, 2001 Disponível em: $<$ http://cardio.bjmu.edu.cn/reference/237.pdf $>$. Acesso em: 24 abr. 2011. doi: 10.1007/s11886-001-0042-9.

ROBINSON, T.F. et al. Skeletal framework of mammalian heart muscle. Laboratory Investigation, v.49, n.4, p.482-498, 1983.
ROSSI, M.A. Fibrosis and inflammatory cells in human cronic chagasic myocarditis: scanning electron microscopy and immunohistochemical observations. International Journal of Cardiology, v.66, p.183-184, 1998.

SÁNCHEZ-QUINTANA, D. et al. Myoarchitecture and connective tissue in hearts with tricuspid atresia. Heart, v.81, n.2, p.182-191, 1999.

SMYTHE, R.H. A psique do cavalo. São Paulo: Varela, 1990. $141 \mathrm{p}$.

VRACKO R. et al. Connective tissue cells in healing rat myocardium. A study of cell reactions in rhythmically contracting environment. American Journal of Pathology, v.134, n.5, p.993-1006, 1989.

WEBER, K.T. et al. Collagen network of the myocardium: function, structural remodeling and regulatory mechanisms. Journal of molecular and cellular cardiology, v.26, p.279292, 1994. Disponível em: <http://www.sciencedirect.com/ science? ob=ArticleURL\& udi=B6WK6-45P0981$3 F \&$.user $=10 \&$ coverDate $=03 \% 2 \mathrm{~F} 31 \% 2 \mathrm{~F} 1994 \&$ rdoc $=1 \&$ f $\mathrm{mt}=$ high\&_orig $=$ gateway \&_origin $=$ gateway $\&$ sort $=\mathrm{d} \&$ docan chor $=\&$ view $=$ c\&_acct $=$ C000050221\&_version $=1 \&$ _urlVersion $=$ $0 \&$ userid $=10 \& \mathrm{md} 5=5 \mathrm{f} 980$ aebe $68 \mathrm{f} 3 \mathrm{f} 5 \mathrm{e} 6 \mathrm{da} 0 \mathrm{~b} 4 \mathrm{e} 61 \mathrm{aceb} 207 \& \mathrm{~s}$ earchtype $=a>$. Acesso em: 24 abr. 2011 doi:10.1006/ jmcc.1994.1036. 